\title{
Curcumin augments the cytostatic and anti-invasive effects of mitoxantrone on carcinosarcoma cells in vitro*
}

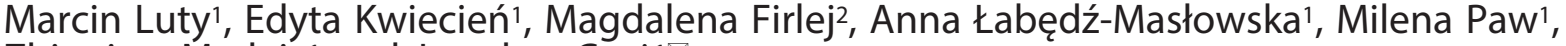 \\ Zbigniew Madeja ${ }^{1}$ and Jarosław Czyż ${ }^{1 凶}$
}

'Department of Cell Biology and 2Department of Microbiology, Faculty of Biochemistry, Biophysics and Biotechnology, Jagiellonian University, Kraków, Poland

\begin{abstract}
Numerous adverse effects limit the applicability of mitoxantrone for the treatment of drug-resistant tumors, including carcinosarcoma. Here, we estimated the additive effects of mitoxantrone and curcumin, a plant-derived biomolecule isolated from Curcuma longa, on the neoplastic and invasive potential of carcinosarcoma cells in vitro. Curcumin augmented the cytostatic, cytotoxic and anti-invasive effects of mitoxantrone on the Walker-256 cells. It also strengthened the inhibitory effects of mitoxantrone on the motility of drug-resistant Walker-256 cells that had retained viability after a long-term mitoxantrone/curcumin treatment. Thus, curcumin reduces the effective doses of mitoxantrone and augments its interference with the invasive potential of drug-resistant carcinosarcoma cells.
\end{abstract}

Key words: carcinosarcoma; mitoxantrone; curcumin; apoptosis; motility

Received: 16 March, 2016; revised: 24 April, 2016; accepted: 06 May, 2016; available on-line: 08 July, 2016

\section{INTRODUCTION}

Mitoxantrone (1,4-dihydroxy-5,8-bis[2-(2-hydroxyethylamino)ethylamino]-anthraquinone; MTX, Fig. 1A) is a derivative of anthraquinone, which inhibits the topoisomerase II activity. It also intercalates into DNA, thus interfering with the proliferation of cancer cells. Apart from cytostatic effects on cancer cells, MTX interferes with the physiology of normal cells, such as macrophages and lymphocytes (Kamm et al., 2014). This results in liver dysfunctions, urinary tract infections, pneumonia and other respiratory tract inflammations (Rivera et al., 2013). Collectively, the adverse effects of MTX impose restrictions on its therapeutic doses and limit the efficiency of MTX for the treatment of drug-resistant tumors. These restrictions can be overcome by combined therapies based on the concomitant application of cytostatic drug(s) and non-toxic biomolecules that sensitize tumor cells to cytostatics (Karp et al., 2012; Koczurkiewicz et al., 2013; Zhao et al., 2015).

Numerous biological activities and a low systemic toxicity of curcumin (((1E, 6E)-1,7-bis (4-hydroxy-3-methoxyphenyl) hepta-1,6-dien-3,5-dione); CC; Fig. 1B) suggested the suitability of this biomolecule for a combined tumor therapy (Wang, 2013; Negi et al., 2014). CC is abundant in Curcuma longa (turmeric) which, due to its anti-inflammatory, antibacterial and cytoprotective activity, is commonly used in traditional Indian medicine (Liu \& Huang, 2012; Prasad et al., 2014; Santos et al., 2015).
For instance, it exerts cytoprotective effects on hepatocytes and inhibits the proliferation of breast, lung and prostate cancer cells, being potentially responsible for a relatively low incidence of these tumors in India (Ide et al., 2010; Chen et al., 2014; Mehrabani et al., 2015). CC also interferes with the progression of advanced colon cancers in the absence of any serious side effects (Sharma et al., 2004) and increases the sensitivity of tumor cells to radiotherapy in vitro and in vivo (Shehzad et al., 2013; Qian et al., 2015). These observations open perspectives for the application of CC as an adjuvant that would reduce the effective doses and adverse effects of MTX, thus overcoming the restrictions of MTX application in tumor treatment.

Till now, MTX has been used in the treatment of breast, cervical and prostate cancers (Szwed, 2014). However, it has been reported as relatively ineffective against carcinosarcoma (Muss et al., 1997, Kanthan \& Senger, 2011). Carcinosarcomas occur most frequently in the female genital tract $5 \%$ of all female genital system cancers), where the clinical 5-year survival rate of patients is only about 50\% (Bigby et al., 2005; Shariftabrizi, et al., 2015), although they may also develop in the bronchi (Carcano et al., 2012) and in the prostate (Furlan et al., 2013). Doxorubicin derivatives, cisplatin and paclitaxel are commonly applied in the carcinosarcoma chemotherapy (Kanthan \& Senger, 2011), in combination with surgical intervention and radiotherapy (Alem et al., 2014, Bigby et al., 2005). However, the effectiveness of these agents decreases during the treatment of distant metastases. We presumed that MTX could still be considered in the treatment of patients with disseminated carcinosarcoma, provided that the MTX effects on tumor cells are strengthened by a concomitant administration of an adjuvant, such as CC.

To verify this notion, we estimated the dose-dependent effects of MTX, CC and of their cocktails on the Walker-256 cells. Carcinosarcomas are comprised of morphologically heterogeneous cells that exhibit both, epithelioid and sarcomatoid properties (Shariftabrizi et al., 2015). The Walker-256 cells reflect the phenotypic diversity of carcinosarcoma because non-adherent, blebbing and lammellipodia-forming (LC), "mesenchymal" Walker-256 lineages have been propagated (Sroka et al.,

e-mail: jarek.czyz@uj.edu.pl

*A preliminary report on this subject has been presented at the Intercollegiate Biotechnology Symposium (IBS) "Symbioza" in Warsaw, 2015 and at the XLIII Winter School of Faculty of Biochemistry, Biophysics and Biotechnology, Jagiellonian University in Zakopane, 2016.

Abbreviations: CC, curcumin; MTX, mitoxantrone 


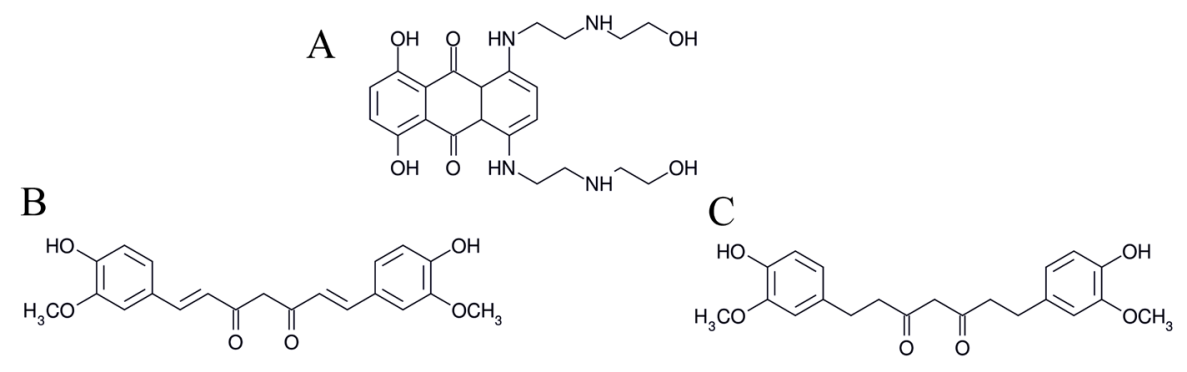

Figure 1. Chemical structure of mitoxantrone (A), curcumin (B) and tetrahydrocurcumin (C).

2002). Due to their relatively strong adhesion and prominent motility, we used LC_Walker-256 cells as a tool for the analysis of additive anti-tumorigenic activities of MTX and CC in relation to the phenotypic heterogeneity of carcinosarcoma. To comprehensively assess these relationships, we focused on selective short-term and longterm effects of both biomolecules on drug-sensitive and drug-resistant cell sub-populations.

\section{MATERIALS AND METHODS}

Curcumin (CC) and mitoxantrone (MTX) treatment of the Walker-256 cells. "Mesenchymal" (lammellipodia-forming (LC)) sub-line of rat carcinosarcoma Walker-256 cells (Sroka et al., 2002) was cultured under standard conditions $\left(37^{\circ} \mathrm{C}, 5 \% \mathrm{CO}_{2}\right)$ in the RPMI medium supplemented with 5\% FBS and antibiotics. For endpoint experiments, media supplemented with CC or MTX alone or with curcumin/MTX cocktails, at the concentrations ranging from $0.1 \mathrm{nM}$ to $100 \mathrm{nM}$ (MTX) and $1.25 \mu \mathrm{M}$ or $2.5 \mu \mathrm{M}$ (CC), were added after $24 \mathrm{~h}$ long cell pre-incubation in the culture medium.

Analyses of cell motility and cytoskeleton. Cell movement was analyzed with an inverted Leica DMI6000B microscope equipped with IMC optics, at $37^{\circ} \mathrm{C}$ in $5 \% \mathrm{CO}_{2}$. Cells were seeded into 12 -well plates at a density of 500 (control and $0.1 \mathrm{nM}$ MTX; $72 \mathrm{~h}$ variant) or 5000 cells $/ \mathrm{cm}^{2}$ (other variants). Velocity of cell movement (total length of cell trajectory/time of recording; $\mu \mathrm{m} / \mathrm{h}$ ) and velocity of cell displacement (i.e. the direct distance from the starting point to the cells' final position/time of recording; $\mu \mathrm{m} / \mathrm{h}$ ) were quantified with the Hiro program. For the visualization of cytoskeleton, the cells were fixed with $3.7 \%$ formaldehyde, Triton-solubilized, stained with mouse anti-vinculin IgG and counterstained with Alexa 488-conjugated goat anti-mouse IgG, TRITC-conjugated phalloidin and Hoechst33258 (all from Sigma). Image acquisition was performed with a Leica DMI6000B microscope (Leica Microsystems, Wetzlar, Germany; Daniel-Wójcik et al., 2008).

Proliferation, cell cycle and apoptosis assays. Cells were seeded into 24- (proliferation assays), 12- (viability tests) or 6-well plates (cell-cycle and apoptosis tests; Corning) at the density of $5 \times 10^{3}$ cells $/ \mathrm{cm}^{2}$ and cultivated in a culture medium for 24 hours. Thereafter, a medium containing MTX (0.1-100 nM) and/or CC (1.25 or $2.5 \mu \mathrm{M})$ was administered for 72 hours; the cells were then harvested, re-suspended in the original culture medium and counted with the Coulter counter (Beckman). Their viability was determined by the fluorescein diacetate/ethidium bromide assays using a Leica DMI6000B microscope in the epifluorescence mode. At least 200 cells were analyzed for each condition. For DNA analyses, cells were stained in plates with Hoechst 33242 (Sigma, $1 \mu \mathrm{g} / \mathrm{ml}$ ) and analyzed as above. Alternatively, suspended and $\mathrm{EtOH}$-fixed $\left(70 \%\right.$ at $\left.-20^{\circ} \mathrm{C}\right)$ cells were stained with propidium iodide (PI; $50 \mu \mathrm{g} / \mathrm{ml}$ ) in the presence of RNAseA. For analyses of apoptosis, cells were subjected to AnnexinV/propidium iodide staining according to the manufacturer's protocol (BD Pharmingen). Flow cytometric analyses of DNA content and detection of apoptotic cells was performed with BD LSR Fortessa X-20 FACS (Koczurkiewicz et al., 2013).

\section{RESULTS AND DISCUSSION}

\section{MTX and CC cooperatively inhibit the motility of LC_ Walker-256 cells}

Time-lapse analyses of short-term effects of mitoxantrone (MTX; 0.1-1.6nM) and curcumin (CC; 1.25 and $2.5 \mu \mathrm{M})$ demonstrated slight additive effects of both agents on motility of the LC_Walker-256 cells. MTX and CC interfered with this parameter in a dose-dependent manner. This effect was illustrated by the reduction of an averaged cell displacement rate to about $55 \%$ and $50 \%$ of control observed in the presence of $1.6 \mathrm{nM}$ MTX and $2.5 \mu \mathrm{M}$ CC, respectively (Fig. 2A). CC/MTX cocktails inhibited the LC_Walker-256 cell motility to the levels observed in the presence of CC or MTX administered alone (at low and high MTX concentrations, respectively), whereas an additive effect of CC could be observed in the presence of $1.6 \mathrm{nM}$ MTX. Cell motility is crucial for cancer invasion; therefore these effects can illustrate anti-invasive effects of both agents exerted at the concentrations corresponding to those observed in the sera of rats after MTX/CC intake (Prasad et al., 2014). The lack of true synergy of MTX/CC activity might result from their converging effects on the signaling pathways that regulate cell motility. Actually, NF- $x \mathrm{~B}-$, PI3K/Akt- and small G protein-dependent pathways are involved in the regulation of cell motility and both agents have been shown to interfere with their activity (Limtrakul et al., 2007; Lin et al., 2010; Bidaud-Meynard et al., 2013; Chen et al., 2014; Seo et al., 2014). However, the less pronounced effects of MTX/CC on cell motility observed 24 hours after their administration (Fig. 2B) attracted our attention to the selective effects of both agents, resulting from phenotypic heterogeneity of the LC_Walker-256 cells.

\section{Curcumin augments long-term cytostatic effects of MTX on LC_Walker-256 cells}

Long-term cytostatic and cytotoxic effects of MTX and CC confirmed the heterogeneous sensitivity of the $\mathrm{LC}_{-}$ Walker-256 cells to the MTX/CC treatment. CC had no effect on the WC-256 viability when administered alone, but a relatively strong and dose-dependent cytotoxic effect of MTX on the LC_Walker-256 cells was observed 
A

Control

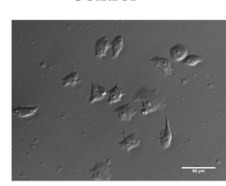

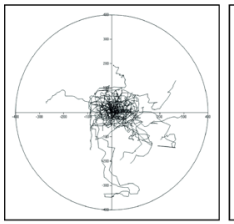

CC $2.5 \mu \mathrm{M}$
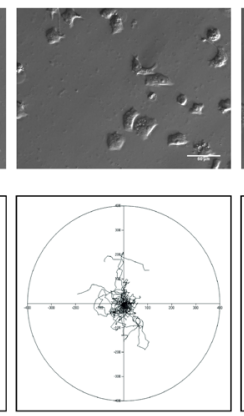

MTX $1.6 \mathrm{nM}$
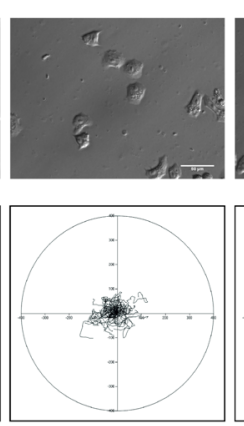
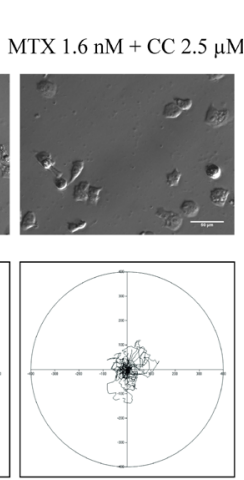
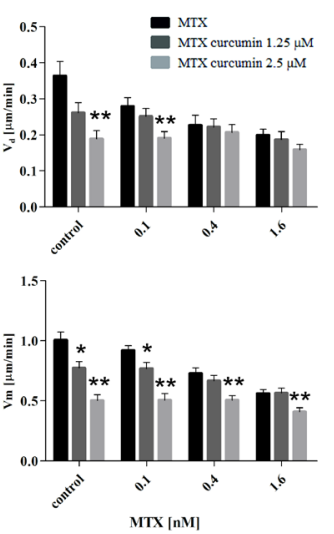

B

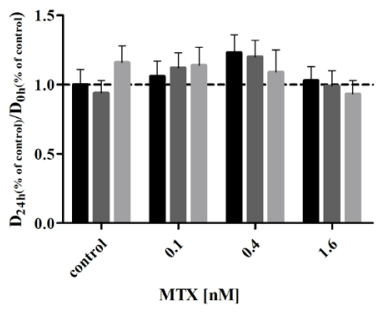

Figure 2. Curcumin and mitoxantrone cooperatively inhibit the LC_Walker-256 cell motility.

Movement of the LC_Walker-256 cells was registered immediately after the administration of media supplemented with MTX and/or CC. At least 50 cell trajectories (360 min at 5 min intervals) were drawn for each condition and presented in circular diagrams with the starting point of each trajectory situated at the plot center. Pictures show representative areas of data acquisition. Column charts summarize the effect of both agents on velocity of cell movement $\left(\mathrm{V}_{\mathrm{m}}\right)$ and displacement $\left(\mathrm{V}_{\mathrm{d}}\right)$, respectively. (B) Cells were cultivated in the medium supplemented with MTX and/or CC for 24 hours and their averaged displacement rates were compared to those observed immediately after drug administration (see A). Statistical significance was estimated with the non-parametric Mann-Whitney test (vs. control; ${ }^{*} P \leq 0.05$; ${ }^{*} P \leq 0.01$ ). Error bars represent SEM. Scale bar: $25 \mu \mathrm{m}$. Results are representative of 3 independent experiments. Note the partial recovery of the cells from the inhibitory effect of MTX/CC on cell motility after their long-term incubation in the presence of MTX and CC.

(Fig. 3A). $2.5 \mu \mathrm{M}$ CC slightly decreased the viability of the WC-256 cells in the presence of $0.1 \mathrm{nM}$ MTX and augmented the cytotoxic effect of $0.4 \mathrm{nM}$ MTX, whereas $1.25 \mu \mathrm{M}$ CC also increased the effect of $0.4 \mathrm{nM}$ MTX. These effects were correlated with the pro-apoptotic activity of MTX, illustrated by micronuclei tests and DNA content staining analyses (Fig. 3B). Fragmentation of cell nuclei and abundant AnnexinV-staining were accompanied by considerable fractions of propidium iodide (PI)-stained cells in the MTX-treated LC_Walker-256 populations, which were further increased by CC (Fig. 3C). Noteworthy, about $10 \%$ of viable (Fig. $3 \mathrm{~A}$ ), non-apoptotic cells (Fig. 3C), could still be observed after a long-term incuba- tion in the presence of the highest MTX/CC concentrations. A considerable fraction of $\mathrm{G}_{2} / \mathrm{M}$ cells in the MTX/ CC-treated LC_Walker-256 populations indicates that a $\mathrm{G}_{2}$-specific apoptosis is induced by both agents and suggests that some cells retain their proliferative activity under such conditions (Fig. 3B). These observations confirm that CC could be applied to reduce the effective doses of MTX in carcinosarcoma treatment, as previously suggested for MTX- and doxorubicin-based prostate, lung and liver cancer therapy (Koczurkiewicz et al., 2013; Zhao et al., 2015). However, such a combined treatment may still result in the propagation of drug-resistant LC_Walker-256 cell sub-population(s).

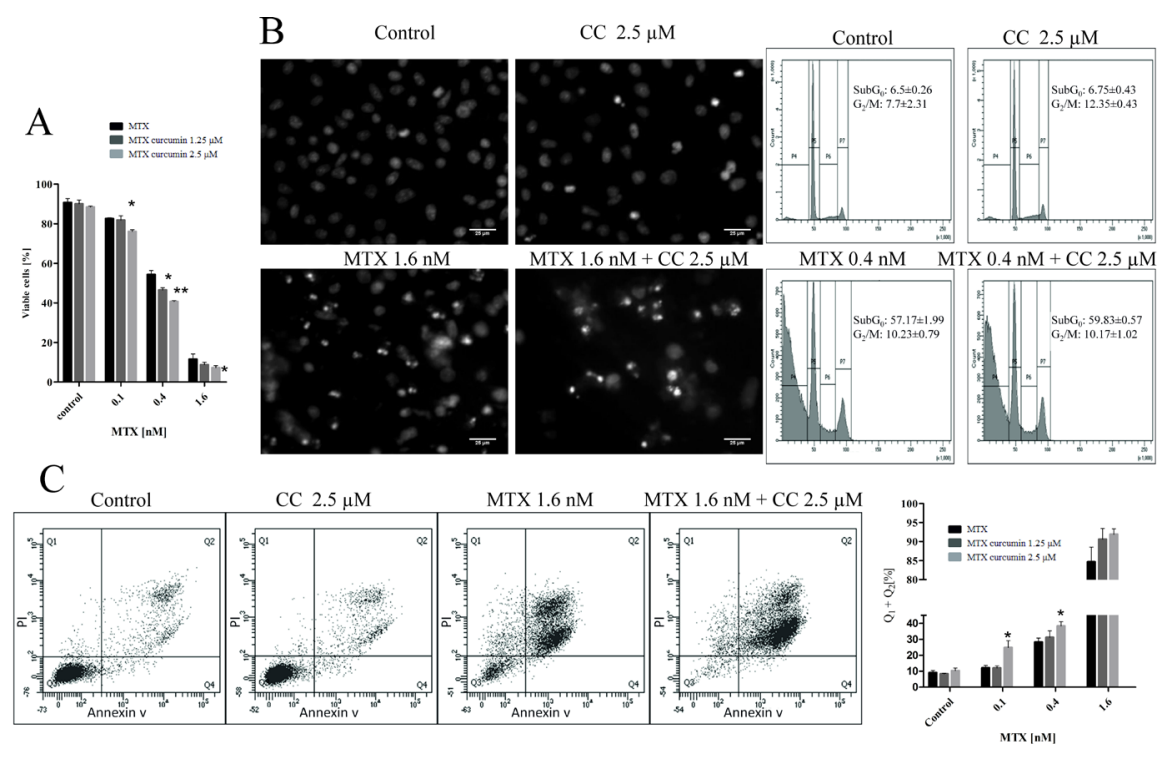

Figure 3. Curcumin and mitoxantrone exert additive cytotoxic and pro-apoptotic effects on the carcinosarcoma LC Walker-256 cells. (A) Cells were cultivated in the presence of MTX and/or CC for $72 \mathrm{~h}$ and subjected to viability tests. Concomitantly, apoptotic cells were visualized with Hoechst33242 and analyzed by FACS-assisted analyses of DNA content (B) or identified by AnnexinV/PI tests (C). Column charts show relative numbers of living (A) and propidium iodide-positive (Q1+Q2) cells (C). Dot-plots show an AnnexinV/PI staining pattern. At least 50000 cells were counted for each experiment. Statistical significance was estimated with the Student's $t$-test (vs. control; $\left.{ }^{*} P \leq 0.05 ;{ }^{*} P \leq 0.01\right)$. Error bars represent SEM. Scale bar: $25 \mu \mathrm{m}$. Results are representative of 3 independent experiments. Note the additive effects of CC and MTX (0.1-0.4 nM), which are accompanied by the presence of non-apoptotic cells after a long-term MTX/CC treatment. 


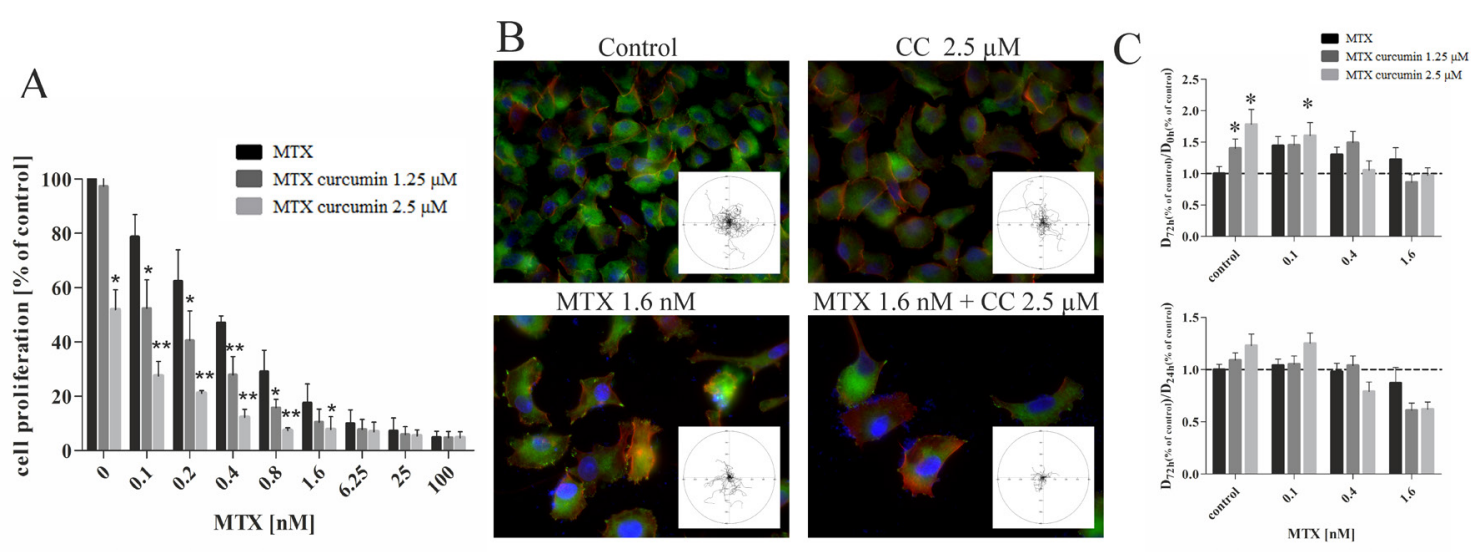

Figure 4. Long-term MTX/CC treatment facilitates the expansion of drug-resistant LC_Walker-256 cell sub-population(s).

(A) 72 hour-long cultivation of the LC Walker-256 cells in the presence of MTX and C $\bar{C}$ was followed by the calculation of their relative numbers with a Coulter counter (control=100\%). (B) Cells were treated with MTX/CC as in A, fixed and stained against vinculin and actin for fluorescence microscopy analyses of their morphology and cytoskeleton architecture. Alternatively, cells were cultivated in the medium supplemented with MTX and/or CC for 72 hours and their movement was registered with a time-lapse videomicroscopy (inserts) and compared to that observed immediately after the drug administration or after 24 h-long treatment (C). Statistical significance was estimated with the non-parametric Mann-Whitney test (vs. control; ${ }^{*} P \leq 0.05 ;{ }^{*} P \leq 0.01$ ). Error bars represent SEM. Scale bar: $25 \mu$ m. Results are representative of 3 independent experiments. Note that a small population of the LC_Walker-256 cells, which had survived a longterm (72 h) MTX/CC treatment, displays a considerably higher motility than after the short-term (0-24 h) MTX/CC regimens. Its motility is inhibited in the presence of $1.6 \mathrm{nM}$ MTX/CC cocktails.

\section{MTX/CC cocktails inhibit the motility of drug-resistant LC_Walker-256 cells}

To unequivocally confirm the selective effects of MTX/CC treatment on the LC_Walker-256 cells, we further analyzed growth curves of the MTX/CC-treated LC_Walker-256 cells and estimated the motile activity of drug-resistant cells. Long-term treatment of the LC_Walker-256 cells with MTX/CC cocktails exerted a considerably stronger effect on cell proliferation than these agents administered alone. This finding confirms the reducing effect of $\mathrm{CC}$ on the effective doses of MTX. Interestingly, a considerable fraction (ca. 10\%) of adherent cells could again be seen in the presence of 100nM MTX, even though CC considerably reduced their numbers (Fig. 4A). This observation is consistent with the data obtained in the viability, cell cycle and apoptosis assays (see Fig. 3), and confirms that a single LC_Walker-256 may be resistant to both agents. Actually, these cells retained morphology and cytoskeleton architecture similar to the control cells, although increased numbers of vinculin-positive focal adhesions were seen in the MTX-treated cells, whereas this effect was not observed in the presence of the MTX/CC cocktails (Fig. 4B). Drug-resistant LC_Walker-256 cells were considerably more motile than the cells analyzed immediately after the MTX/CC administration (Fig. 4C, cf. Fig. 2). Whereas the role of MTX/CC effects on MDR mechanisms remains to be elucidated (Mapoung et al., 2016), our data demonstrate the phenotypic heterogeneity of the LC_Walker-256 sub-populations and show that the MTX/CC treatment leads to the selection of drug-resistant cells. This observation remains in contrast to the effects of tetrahydrocurcumin (Fig. 1C) that has been shown to attenuate tumor cell resistance to MTX (Limtrakul et al., 2007). It indicates that CC does not completely eliminate the expansion of MTX-resistant cells. On the other hand, a considerable inhibition of cell motility was still observed after a long-term incubation of the LC_Walker-256 cells in the presence of $1.6 \mathrm{nM}$ MTX $/ 2.5 \mu \mathrm{M}$ CC cocktail (Fig. 4B, C). Our data indicate that $\mathrm{CC}$ not only reduces the effective cytotoxic doses of MTX, but also affects the invasive potential of
MTX-resistant cells. Noteworthy, $2.5 \mu \mathrm{M}$ CC can exceed the serum concentrations observed in humans after CC uptake, therefore alternative routes of CC administration and/or application of the formulated curcumin (nanoemulsion, nanocapsules etc.) may be necessary to achieve its full systemic activity (Prasad et al., 2014).

\section{SUMMARY AND OUTCOME}

An approach based on a combined application of cytostatic drugs and phytochemicals is a promising tool in the therapy of drug-resistant tumors. Plant-derived biomolecules (such as curcumin) display a relatively low systemic toxicity and can sensitize tumor cells to extrinsic cytostatic cues. Therefore, they can be applied to augment the bioactivity of chemotherapeutic drugs, thus reducing their effective doses and potentially prolonging the expected life-span and the patient standard of living (Sarkar et al., 2006). The augmenting effects of CC on carcinosarcoma cell sensitivity to MTX, along with antiinflammatory and hepatoprotective activity of CC (ElBahr 2014; Santos et al., 2015), indicate a potential of the MTX/CC cocktails for elaboration of a "gold standard" or at least of the $2^{\text {nd }}$ line of chemotherapeutic approaches against carcinosarcoma. Anti-angiogenic activity of CC (Gong et al., 2013; Li et al., 2005) may also counteract the pro-angiogenic MTX effects. Therefore, this biomolecule could also be used as an adjuvant in metronomic MTX-based anti-carcinosarcoma approaches. CC does not completely eliminate the expansion of MTX-resistant cells, however it exerts additive inhibitory effects on their motility. It may indicate that CC could slow down the tumor progression that results from the chemotherapy-induced microevolution of drug-resistant, invasive tumor cell sub-populations.

\section{Acknowledgement}

The Faculty of Biochemistry, Biophysics and Biotechnology of the Jagiellonian University is a partner of the Leading National Research Center (KNOW) supported by the Ministry of Science and Higher Education. 
This work was financially supported by the "Student Research Project" sponsored by the Faculty of Biochemistry, Biophysics and Biotechnology of Jagiellonian University (to M. Luty) and the Polish National Science Centre (grant 2015/17/B/NZ3/01040 to J. Czyż).

\section{Conflicts of interest}

The authors declare no conflict of interest.

\section{REFERENCES}

Alem HB, AlNoury MK (2014) Management of spindle cell carcinoma of the maxillary sinus: a case report and literature review. Am J Case Rep 15: 454-458. http://doi.org/10.12659/AJCR.891007.

Bidaud-Meynard A, Arma D, Taouji S, Laguerre M, Dessolin J, Rosenbaum J, Chevet E, Moreau V (2013) A novel small-molecule screening strategy identifies mitoxantrone as a RhoGTPase inhibitor. Biochem I 62: 55-62. http://doi.org/10.1042/BJ20120572.

Bigby SM, Charlton A, Miller MV, Zwi LJ, Oliver GF (2005) Biphasic sarcomatoid basal cell carcinoma (carcinosarcoma): four cases with immunohistochemistry and review of the literature. J Cutan Pathol 32: 141-147. http://doi: 10.1111/j.0303-6987.2005.00276.x.

Carcano C, Savage E, Diacovo MJ, Kirsch J (2012) Bronchial carcinosarcoma, J Radiol Case Rep 6: 26-31. http://doi.org/10.3941/jrcr. v6i10.1049.

Chen B, Zhang Y, Wang Y, Rao J, Jiang X, Xu Z (2014) Curcumin inhibits proliferation of breast cancer cells through Nrf2-mediated down-regulation of Fen1 expression. I Steroid Biochem Mol Biol 143: 11-18. http://doi.org/10.1016/j.jsbmb.2014.01.009.

Chen QY, Zheng Y, Jiao DM, Chen FY, Hu HZ, Wu YQ, Song J, Yan J, Wu LJ, Lv GY (2014) ScienceDirect Curcumin inhibits lung cancer cell migration and invasion through Rac1-dependent signaling pathway. J Nutritional Biochem 25: 177-185. http://doi. org/10.1016/j.jnutbio.2013.10.004.

Daniel-Wójcik A, Misztal K, Bechyne I, Sroka J, Miekus K, Madeja Z, Czyz J (2008) Cell motility affects the intensity of gap junctional coupling in prostate carcinoma and melanoma cell populations. Int J Oncol 33: 309-315. http://doi.org/10.3892/ijo.

El-Bahr SM (2014) Effect of curcumin on hepatic antioxidant enzymes activities and gene expressions in rats intoxicated with aflatoxin B1. Phytother Res 29. http://doi: 10.1002/ptr.5239. Epub 2014 Oct 8.

Furlan SR, Kang DJ, Armas A (2013) Prostatic carcinosarcoma with Lung Metastases. Case Rep Oncol Med 1-3. http://doi; 10.1155/2013/790790.

Gong C, Deng S, Wu Q, Xiang M, Wei X, Li L, Gao X, Wang B, Sun L, Chen Y, Li Y, Liu L, Qian Z, Wei Y (2013). Biomaterials Improving antiangiogenesis and anti-tumor activity of curcumin by biodegradable polymeric micelles. Biomaterials 34: 1413-1432. http:// doi.org/10.1016/j.biomaterials.2012.10.068

Ide H, Yu J, Lu Y, China T, Kumamoto T, Koseki T, Muto S, Horie S (2010) Testosterone augments polyphenol-induced DNA damage response in prostate cancer cell line. LNCaP. Cancer Sci 102: 468471 http://doi.org/10.1111/j.1349-7006.2010.01791.x.

Kamm CP, Uitdehaag BM, Polman CH. C. H. (2014) Multiple sclerosis: current knowledge and future outlook. Eur Neurol 72: 132-141. http://doi.org/10.1159/000360528.

Kanthan R, Senger JL (2011) Uterine carcinosarcomas (malignant mixed müllerian tumours): a review with special emphasis on the controversies in management. Obstet Gynecol Int 2011: 470795. http://doi.org/10.1155/2011/470795.

Karp JE, Garrett-Mayer E, Estey EH, Rudek MA, Smith BD, Greer JM, Drye DM, Mackey K, Dorcy KS, Gore SD, Levis MJ, McDevitt MA, Carraway HE, Pratz KW,Gladstone DE, Showel MM, Othus M, Doyle LA, Wright JJ, Pagel JM (2012) Randomized phase II study of two schedules of flavopiridol given as timed sequential therapy with cytosine arabinoside and mitoxantrone for adults with newly diagnosed, poor-risk acute myelogenous leukemia. Haematologica 97: 1736-1742. http://doi.org/10.3324/haematol.2012.062539.

Koczurkiewicz P, Podolak I, Wójcik KA, Galanty A, Madeja Z, Michalik M, Czyż J (2013) Lclet 4 enhances pro-apoptotic and anti-invasive effects of mitoxantrone on human prostate cancer cells - in vitro study. Acta Biochim Pol 60: 331-338.

Li L, Braiteh FS, Kurzrock R (2005) Liposome-encapsulated curcumin in vitro and in vivo effects on proliferation, apoptosis, signaling, and angiogenesis. Cancer 104: 1322-1331. http://doi.org/10.1002/ cncr. 21300 .

Limtrakul P, Chearwae W, Shukla S, Phisalphong C, Ambudkar SV (2007) Modulation of function of three ABC drug mitoxantrone resistance protein (ABCG2) and multidrug resistance protein 1 (ABCC1) by tetrahydrocurcumin, a major metabolite of curcumin. Mol Cell Biochem 296: 85-95. http://doi.org/10.1007/s11010-0069302-8.
Lin HJ, Su CC, Lu HF, Yang JS, Hsu SC, Ip SW, Wu JJ, Li YC, Ho CC, Wu CC, Chung JG (2010) Curcumin blocks migration and invasion of mouse-rat hybrid retina ganglion cells (N18) through the inhibition of MMP-2, -9, FAK, Rho A and Rock-1 gene expression. Oncol Rep 23: 665-670. http://doi.org/10.3892/or.

Liu CH, Huang HY (2012) Antimicrobial activity of curcumin-loaded myristic acid microemulsions against Staphylococcus epidermidis. Chem Pharm Bull (Tokyo) 60: 1118-1124.

Mapoung S, Pitchakarn P, Yodkeeree S, Ovatlarnporn C, Sakorn N, Limtrakul P (2016) Chemosensitizing effects of synthetic curcumin analogs on human multi-drug resistance leukemic cells. Chemico-Biological Interactions 244: 140-148. http://doi.org/10.1016/j. cbi.2015.12.001.

Mehrabani D, Farjam M, Geramizadeh B, Tanideh N, Amini M, Panjehshahin MR. (2015) The Healing effect of curcumin on burn wounds in rat. World J Plast Surg 4: 29-35.

Muss HB, Bundy BN, Homesley HD, Wilbanks G (1987) Mitoxantrone in the treatment of advanced non-squamous carcinoma of the cervix (A phase II trial of the gyneVol-ogic oncology group). Invest New Drugs 5: 199-202.

Negi N, Prakash P, Gupta ML, Mohapatra TM (2014) Possible role of curcumin as an efflux pump inhibitor in multi drug resistant clinical isolates of Pseudomonas aeruginosa. J Clin Diagn Res 8: 8-11. http:// doi.org/10.7860/JCDR/2014/8329.4965.

Prasad S, Tyagi AK, Aggarwal BB (2014) Recent developments in delivery, bioavailability, absorption and metabolism of curcumin: the golden pigment from golden spice. Cancer Res Treat 46: 2-18. http://doi: 10.4143/crt.2014.46.1.2.

Qian Y, Ma J, Guo X, Sun J, Yu Y, Cao B, Zhang L, Ding X, Huang J, Shao JF (2015) Curcumin enhances the radiosensitivity of U87 cells by inducing DUSP-2 up-regulation. Cell Physiol Biochem 35: 1381-1393. http://doi.org/10.1159/000373959.

Rivera VM, Jeffery DR, Weinstock-Guttman B, Bock D, Dangond F (2013) Results from the 5-year, phase IV RENEW (Registry to Evaluate Novantrone Effects in Worsening Multiple Sclerosis) study. BMC Neurology 13: 80. http://doi.org/10.1186/1471-2377-1380 .

Santos AM, Lopes T, Oleastro M, Gato IV, Floch P, Benejat L, Chaves P, Pereira T, Seixas E, Machado J, Guerreiro AS (2015) Curcumin inhibits gastric inflammation induced by Helicobacter pylori infection in a mouse model. Nutrients 7: 306-320. http://doi.org/10.3390/ nu7010306.

Sarkar FH, Li Y (2006) Using chemopreventive agents to enhance the efficacy of cancer therapy. Cancer Res 66: 3347-3351. http://doi. org/10.1158/0008-5472.CAN-05-4526.

Seo BR, Min KJ, Cho IJ, Kim SC, Kwon TK (2014) Curcumin significantly enhances dual PI $3 \mathrm{~K} / \mathrm{Akt}$ and mTOR inhibitor NVPBEZ235-induced apoptosis in human renal carcinoma caki cells through down-regulation of p53-dependent $\mathrm{Bcl}-2$ expression and inhibition of Mcl-1 protein stability. PLoS One 9. http://doi. org/10.1371/journal.pone.0095588.

Shariftabrizi A, Pellicciotta I, Abdullah A, Venditti CA, Samuelson R, Shahabi S (2015) Presence of both mesenchymal and carcinomatous features in an in-vitro model of ovarian carcinosarcoma derived from patients' ascitic fluid. Int J Hematol Oncol Stem Cell Res 9: 3-6.

Sharma RA, Euden SA, Platton SL, Cooke DN, Shafayat A, Hewitt HR, Marczylo TH, Morgan B, Hemingway D, Plummer SM, Pirmohamed M, Gescher AJ,Steward WP (2004) Phase I clinical trial of oral curcumin: biomarkers of systemic activity and compliance. Clin Cancer Res 10: 6847-6854. http:// doi: 10.1158/1078-0432.CCR-040744.

Shehzad A, Park JW, Lee J, Lee YS (2013) Curcumin induces radiosensitivity of in vitro and in vivo cancer models by modulating premRNA processing factor 4 (Prp4). Chemico-biological interactions 206: 394-402. http://doi.org/10.1016/j.cbi.2013.10.007.

Sroka J, von Gunten M, Dunn GA, Keller HU (2002) Phenotype modulation in non-adherent and adherent sublines of Walker carcinosarcoma cells: the role of cell-substratum contacts and microtubules in controlling cell shape, locomotion and cytoskeletal structure. Int J Biochem Cell Biol 34: 882-899.

Szwed, M (2014) Mitoxantrone - an anthraquinone antibiotic with antitumor activity applied for the treatment of multiple sclerosis. Postepy Hig Med Dosw (Online) 68: 198-208.

Wang BL, Shen YM, Zhang QW, Li YL, Luo M, Liu Z, Li Y, Qian ZY, Gao X, Shi HS (2013) Codelivery of curcumin and doxorubicin by MPEG-PCL results in improved efficacy of systemically administered chemotherapy in mice with lung cancer. Int J Nanomedicine 8: 3521-3531.

Zhao X, Chen Q, Liu W, Li Y, Tang H, Liu X, Yang X (2015) Codelivery of doxorubicin and curcumin with lipid nanoparticles results in improved efficacy of chemotherapy in liver cancer. Int J Nanomedicine 10: 257-270. http://doi: 10.2147/IJN.S73322. 